VINHETA IMAGENOLÓGICA

IMAGENOLOGIC VIGNETTE

Responsáveis: Artur da Rocha Corrêa Fernandes e Jamil Natour

\title{
Quadril Doloroso na Criança
}

\section{Painful Hip in Children}

\author{
Cristiane Soares Zoner ${ }^{(1)}$, Érica Narahashi ${ }^{(1)}$, Eduardo Honda ${ }^{(1)}$, Henrique Lederman ${ }^{(1)}$, Maria Odete Esteves
} Hilário $^{(2)}$, Denise Tokechi Amaral ${ }^{(1)}$, Artur da Rocha Corrêa Fernandes ${ }^{(1)}$, Jamil Natour ${ }^{(3)}$

\section{INTRODUÇÃO}

A dor no quadril na criança é um motivo comum de consultas médicas e, muitas vezes, representa um desafio diagnóstico. Isso porque pode estar relacionada a inúmeras causas (Tabela 1) que variam da relativamente inócua sinovite transitória do quadril até artrite séptica, epifisiólise e doença de Perthes, que podem levar a seqüelas com danos estruturais e funcionais.

\section{TABela 1}

CAUSAS DE DOR ISOLADA NO QUADRIL EM CRIANÇAS

\begin{tabular}{l} 
Sinovite transitória \\
Epifisiólise \\
Doença de Perthes \\
Artrite séptica piogênica \\
Artrite tuberculosa \\
Osteomielite \\
Artrite reumatóide juvenil \\
Condrólise idiopática \\
Protrusão acetabular idiopática \\
Trauma \\
Displasia do quadril \\
Osteoma osteóide \\
Osteonecrose \\
Tumores \\
Osteoporose transitória aguda \\
Síndromes não-orgânicas \\
\hline Hollingworth, P. British Journal of Rheumatology 1995; 34:78 (1)
\end{tabular}

Palavras-chave: quadril, criança, RX, ultra-som, ressonância magnética, tomografia computadorizada

\section{SINOVITE TRANSITÓRIA DO QUADRIL}

A sinovite transitória do quadril é uma afecção benigna, autolimitada, de origem desconhecida e representa cerca de $90 \%$ dos casos de dor no quadril na criança. Mais da metade dos casos apresenta antecedente de infecção do trato respiratório superior (cerca de duas a três semanas antes do início dos sintomas) ou trauma leve $\mathrm{e}^{(2)}$. A idade de acometimento varia de 18 meses a 13 anos, mas concentrase principalmente na faixa de 3 a 8 anos.

A febre, quando presente, é baixa. O quadro laboratorial é normal ou apresenta sinais não-específicos de processo inflamatório leve (discreta elevação da VHS - velocidade de hemossedimentação - , leucócitos ou PCR - proteína $\mathrm{C}$ reativa). Na maioria, a resolução ocorre em até duas semanas.

O diagnóstico é de exclusão. A ultra-sonografia evidencia derrame articular anecogênico ou com debris. A radiografia pode mostrar alargamento do espaço articular e ajuda a excluir outras afecções do quadril (Figura 1). Outros exames de imagem geralmente não são necessários. Em casos de suspeita de sépsis, a punção articular está indicada.

\section{ARTRITE SÉPTICA}

A artrite séptica do quadril representa urgência médica com necessidade de diagnóstico e início da terapêutica de forma rápida, para evitar destruição da cabeça femoral. A instituição do tratamento dentro de quatro dias do início dos sintomas está associada a bons resultados, enquanto um retardo de cinco ou mais dias está associado a mau resultado 

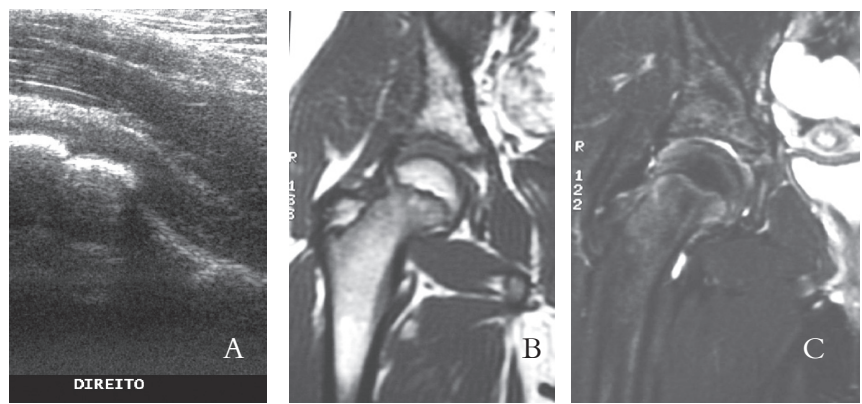

Figura 1 - Sinovite transitória: Ultra-sonografia (A) e RM ponderada em T1 (B) e T2 (C) mostram derrame articular

funcional. As manifestações clínicas podem ser semelhantes à sinovite transitória, porém a dor e a febre são mais acentuadas na maioria. Cerca de $70 \%$ das crianças têm 4 anos ou menos. A temperatura, VHS, proteína C reativa e contagem de leucócitos geralmente estão elevadas.

A ultra-sonografia demonstra derrame articular com ou sem debris. Espessamento sinovial e debris podem ser vistos na artrite séptica, enquanto o líquido é geralmente claro e espessamento sinovial mínimo ou ausente na sinovite transitória. A ressonância magnética (RM) auxilia bastante o diagnóstico, que é definido pela punção articular (Figura 2). A radiografia pode mostrar alargamento da articulação, aumento de partes moles, deslocamento dos planos gordurosos na fase inicial. Sinais de destruição óssea levam cerca de 10 a 14 dias para serem detectados à radiografia.

\section{DOENÇA DE PERTHES}

A doença de Perthes é uma osteonecrose da epífise proximal do fêmur. Ocorre predominantemente em meninos (4:1), com idade variando de 2 a 13 anos, com pico de
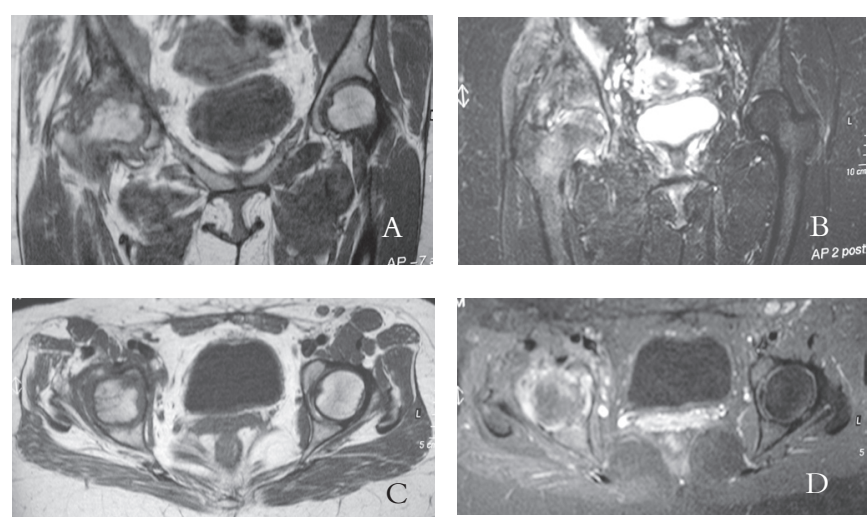

Figura 2 - Artrite séptica: RM nos planos coronal e axial, ponderadas em T1, T2 e T1 com saturação de gordura, após gadolínio, evidenciam derrame articular, sinovite, irregularidade e destruição da cabeça femoral e acetábulo à direita apresentação na faixa de 4 a 9 anos. Em cerca de 15\% dos casos, o acometimento é bilateral. O quadro laboratorial é normal.

A ultra-sonografia pode mostrar derrame articular e irregularidade da epífise, porém o diagnóstico é considerado pelas alterações detectadas à radiografia como linha radiotransparente subcondral ("sinal do crescente"), colapso e esclerose da cabeça femoral e fragmentação da epífise. No estágio final, ocorre reossificação completa da cabeça femoral com deformidade residual. Os achados à RM são mais precoces e caracterizados por baixo sinal em T1 e alto sinal em T2 na cabeça femoral. Com a evolução da doença, a intensidade de sinal torna-se mais heterogênea e desigual, provavelmente relacionada à reparação e formação de tecido de granulação( ${ }^{(6)}$ (Figura 3).
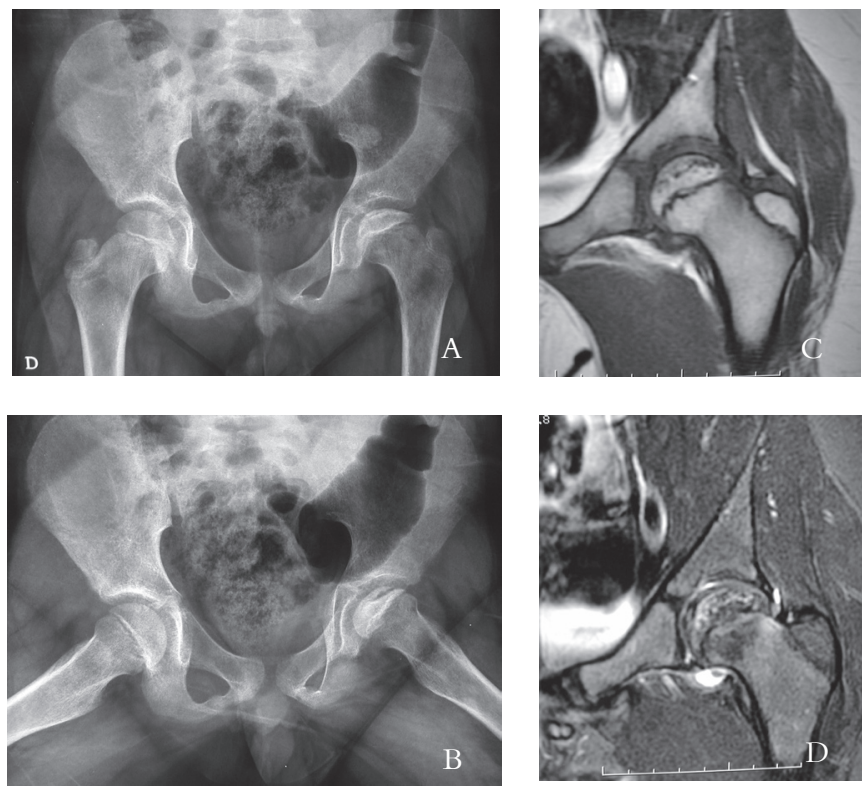

Figura 3 - Doença de Perthes. Radiografias AP (A) e "incidência em rã" (B) demonstram esclerose, irregularidade e remodelação da epífise femoral esquerda. A RM no plano coronal ponderada em T1(C) e T2(D) mostra sinal heterogêneo da epífise femoral

\section{EPIFISIÓLISE}

A epifisiólise é caracterizada pelo deslizamento da epífise femoral. O pico de incidência é de 11,5 anos para meninas e 13 anos para meninos, sendo cerca de duas vezes mais comum no sexo masculino. Ao exame clínico, o paciente apresenta dor na região do quadril ou joelho, com limitação da rotação interna e da abdução. Durante a marcha, o paciente claudica com o membro comprometido em atitude de rotação externa ${ }^{(11)}$. 
A ultra-sonografia pode evidenciar derrame articular e deslizamento epifisário. A radiografia demonstra deslizamento da epífise, alargamento e irregularidade da placa epifisária. Sinais secundários não-específicos como atrofia da musculatura e desmineralização óssea podem estar presentes. O deslizamento pode ser sutil e muitas vezes é mais evidente na incidência "em perna de rã".

O papel da RM em estabelecer o diagnóstico desta afecção é mínimo, embora possa claramente demonstrar o deslizamento em casos questionáveis à radiografia. Alterações edematosas na epífise e metáfise adjacente também podem ser vistas. A RM também pode ser útil no diagnóstico de necrose avascular ou condrólise, que são complicações conhecidas da epifisiólise ${ }^{(6)}$ (Figura 4).
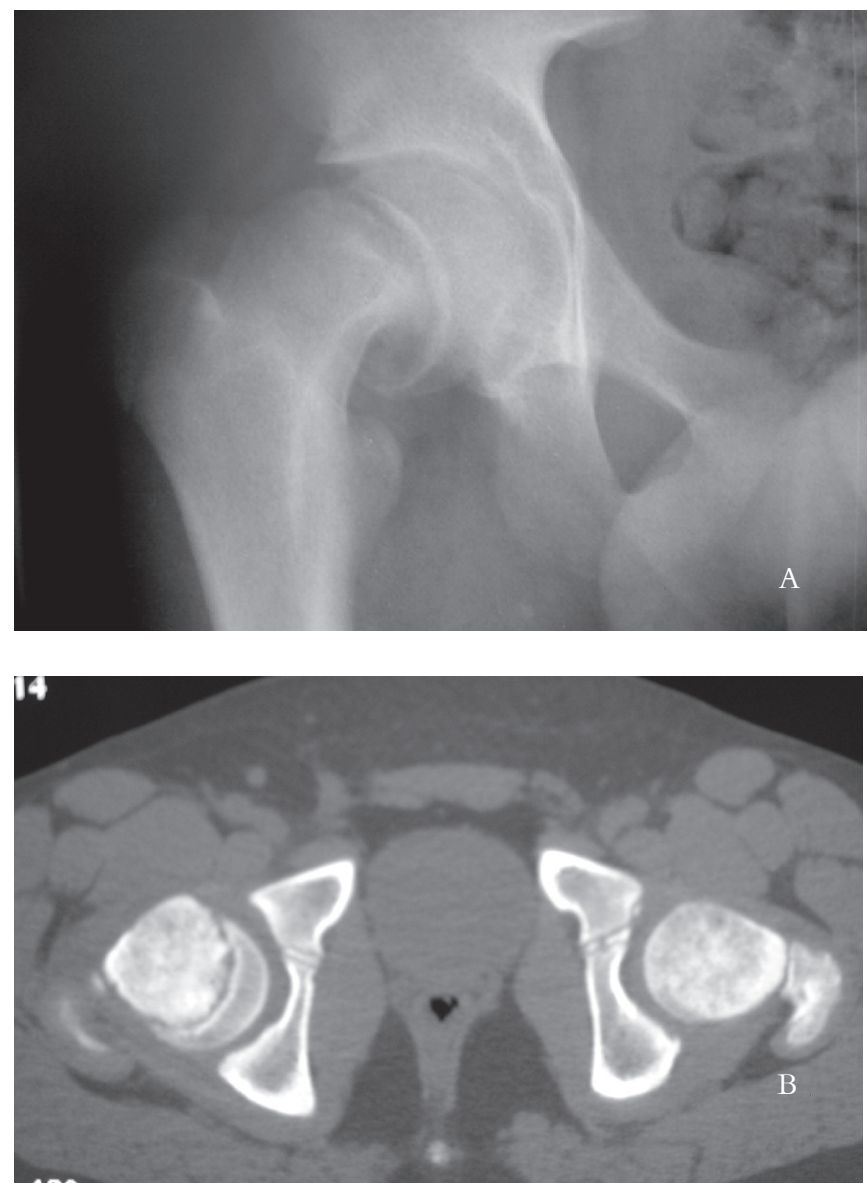

Figura 4 - Epifisiólise. Aspecto típico do deslizamento da epífise femoral direita à radiografia $(A)$ e TC $(B)$

\section{ARTRITE IDIOPÁTICA JUVENIL}

$\mathrm{O}$ acometimento isolado do quadril é uma forma ocasional de apresentação da artrite idiopática juvenil, geralmente ocorrendo em meninos acima de 8 anos. Na maioria dos casos, há progressão para artrite pauciarticular através do comprometimento de outras articulações dos membros inferiores ${ }^{(1)}$.

A ultra-sonografia pode demonstrar derrame articular e/ou espessamento sinovial.

A RM é capaz de detectar alterações sinoviais e de partes moles precocemente, antes do desenvolvimento de alterações ósseas. As alterações encontradas são inflamação sinovial, derrame articular e destruição da cartilagem articular. A sinovite crônica apresenta-se com baixo sinal em T1 e T2, enquanto o derrame e sinovite aguda demonstram baixo sinal em T1 e alto sinal em T2. A injeção endovenosa de gadolínio ajuda a diferenciar líquido da sinovite e pannus. A RM também é útil em mostrar alterações ósseas que ocorrem mais tardiamente no curso da doença, incluindo erosões, estreitamento do espaço articular e cistos subcondrais $^{(6)}$ (Figura 5).
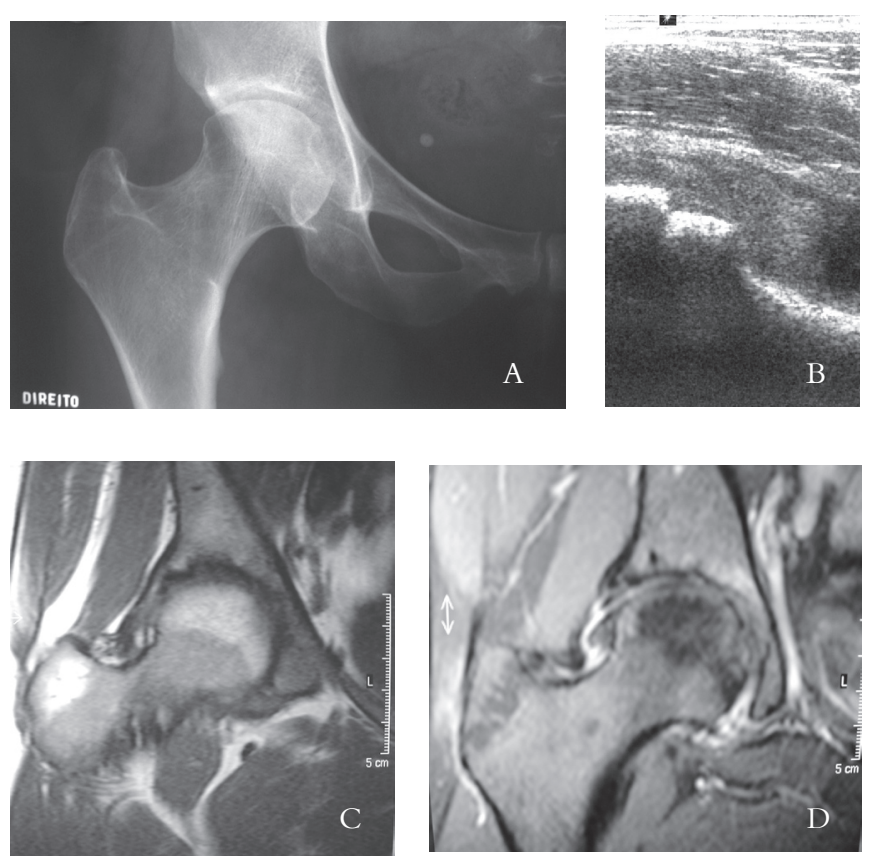

Figura 5 - Artrite Idiopática Juvenil. Radiografia (A) e RM ponderadas em T1, sem supressão de gordura (C) e com supressão (D) após gadolínio evidenciam redução do espaço articular, irregularidade do acetábulo e cabeça femoral e sinovite. A ultra-sonografia (B) demonstra derrame articular associado a espessamento sinovial

\section{FRATURAS-AVULSÕES}

São fraturas através da cartilagem das epífises ou apófises após lesão direta nos locais de inserção dos tendões, ocorrendo especialmente em crianças e adolescentes praticantes de 
esporte. Os principais músculos comprometidos são reto femoral, iliopsoas, adutor magno e sartório.

A radiografia permite o diagnóstico na maioria dos casos, porém as avulsões sem fragmentos ósseos visíveis podem ser dificeis de detectar, sendo vista apenas reabsorção óssea reativa após alguns dias. Avaliação por RM geralmente não é necessária, sendo que as lesões por avulsões podem ter aspecto agressivo à RM e simular processos como tumor e infecção. História e radiografia convencional são comumente suficientes para diagnóstico apropriado ${ }^{(10)}$ (Figura 6).
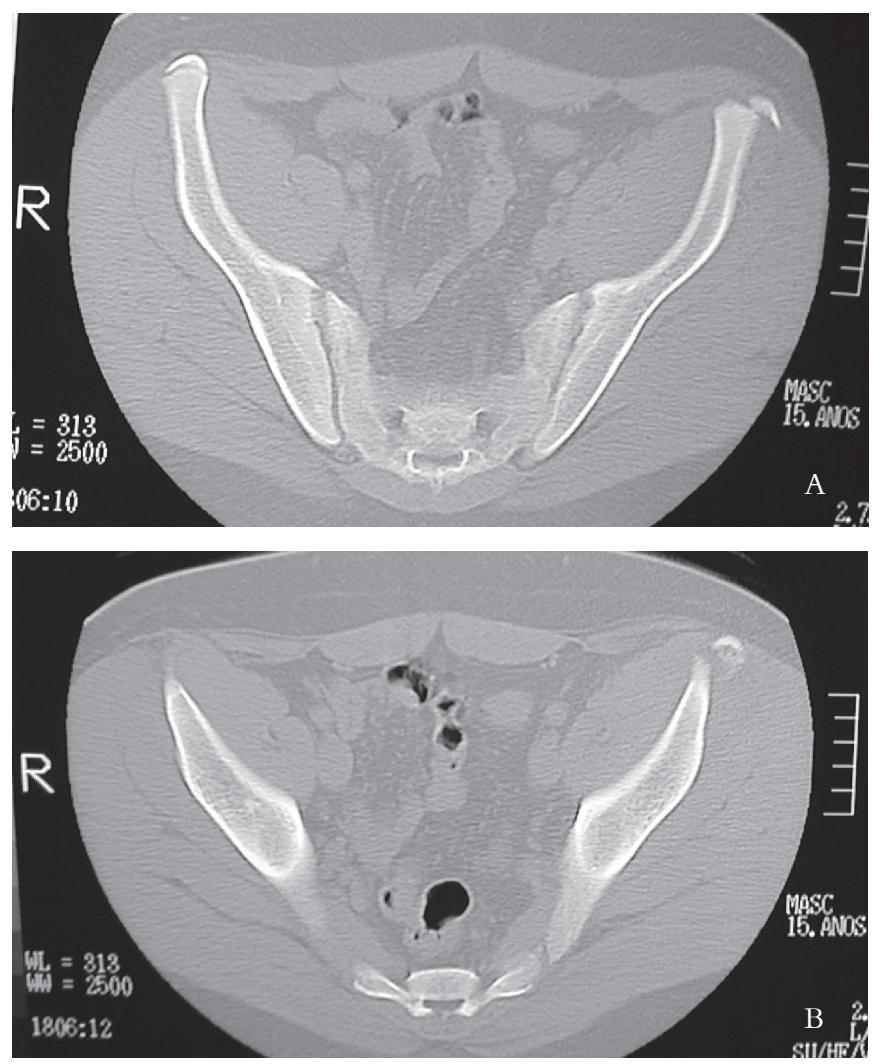

Figura 6 - Fratura-avulsão. TC mostra aspecto da fratura-avulsão da espinha ilíaca

\section{CONDRÓLISE IDIOPÁTICA}

Ocorre tipicamente em adolescentes do sexo feminino. Sintomas sistêmicos e alterações laboratoriais estão ausentes.

As anormalidades radiológicas mais precoces são osteoporose, perda da cartilagem e borramento do osso subcondral. Posteriormente, há fechamento prematuro da epífise, protusão acetabular, osteoartrose e finalmente anquilose. A VHS é normal.

A principal característica encontrada à RM é a perda da cartilagem, inicialmente focal e central, mais acentuada na superfície femoral, com progressão para periferia e comprometendo ambos os lados da articulação na evolução. Remodelação óssea, edema de medula óssea, atrofia muscular e derrame articular em pequena quantidade também são demonstrados ${ }^{(7)}$. Realce sinovial ocorre apenas em alguns casos e a ausência deste pode ajudar a diferenciar de artrite idiopática juvenil e artrite séptica (Figura 7).
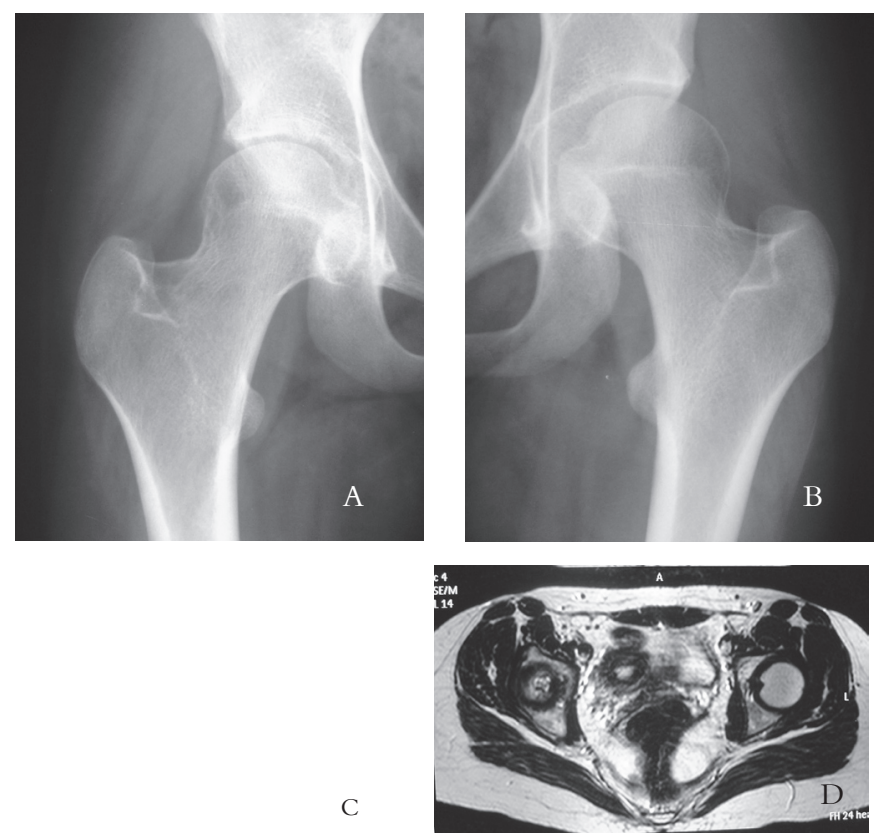

Figura 7 - Condrólise Idiopática. Radiografias (A,B e C) mostram redução do espaço articular à direita. RM (D) demonstra edema da medula óssea da cabeça femoral e acetábulo, derrame articular e redução do espaço articular

\section{PROTUSÃO ACETABULAR IDIOPÁTICA DO QUADRIL}

Meninas atletas na fase pré-pubere são as mais comumente afetadas. A radiografia inicial mostra protusão acetabular unilateral bem estabelecida. A progressão do quadro ocorre rapidamente com acometimento bilateral em cerca de 18 meses. A acentuação da concavidade da linha iliopúbica no nível da cartilagem triangular é considerada fenômeno normal visto em crianças entre 4 e 12 anos de idade ${ }^{(8)}$.

\section{OSTEOPOROSE TRANSITÓRIA DO QUADRIL}

Todos os casos descritos foram em crianças acima de 10 anos, apresentando osteoporose à radiografia e aumento da captação com cintilografia óssea. Alguns autores consideram esta entidade como manifestação regional de algoneurodistrofia 
ou distrofia simpático reflexa ou dor complexa regional.

A RM mostra padrão difuso de edema de medula óssea envolvendo a cabeça femoral, colo e, por vezes, a região intertrocantérica. O acometimento do acetábulo é leve. Pequeno derrame articular está invariavelmente presente. A alteração de sinal pode ser difusa ou poupar um segmento da cabeça femoral. As alterações da intensidade de sinal são freqüentemente heterogêneas, particularmente em T2. A RM mostra a osteoporose transitória mais precocemente do que a radiografia ${ }^{(9)}$.

\section{OSTEOMA OSTEÓIDE}

O osteoma osteóide tem predileção pela porção proximal do fềmur, apresentando-se como dor subaguda ou recorrente, tipicamente noturna e caracteristicamente aliviada por salicilatos em adolescentes.

A radiografia pode ou não demonstrar o nidus radiotransparente com esclerose marginal reacional. A tomografia computadorizada (TC) é o exame de escolha para localização do nidus (Figura 8).

O osteoma osteóide do colo femoral freqüentemente simula outras anormalidades à RM e a aparência destas lesões é variável. Na maioria dos casos, o nidus aparece como foco de baixo sinal em T1 e T2. Grau variável de edema pode estar presente, variando de completa ausência de edema até quantidade que pode obscurecer um nidus pequeno. Este aspecto pode imitar outras formas de edema, como a osteoporose transitória ${ }^{(6)}$.
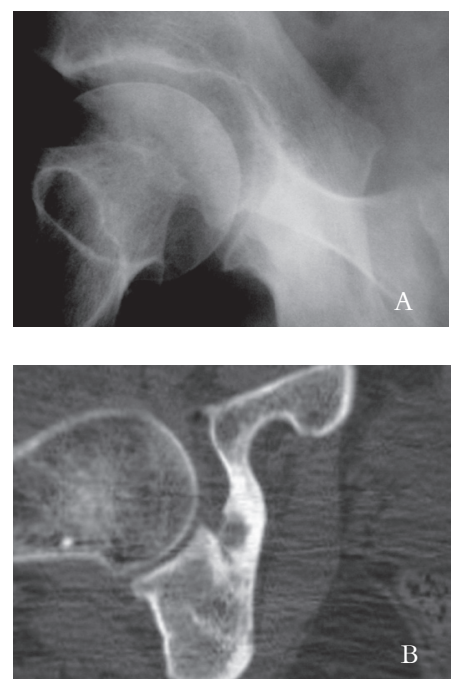

Figura 8 - 0steoma osteóide. A radiografia (A) demonstra esclerose borda medial do acetábulo, porém nidus não é evidente. A TC (B) evidencia área focal arredondada radiotransparente (nidus) no acetábulo, com esclerose reacional

\section{DISCUSSÃO}

A dor no quadril é uma queixa comum na população pediátrica, representando cerca de $4 \%$ das consultas ao reumatologista pediátrico ${ }^{(1)}$, e a sinovite transitória é a afecção mais prevalente. A principal preocupação é fazer o diagnóstico dos casos graves evitando-se, sempre que possível, exames e procedimentos invasivos desnecessários.

Várias estratégias foram propostas para avaliação de crianças com dor no quadril. Swischuk ${ }^{(4)}$ sugere avaliação inicial com radiografia dos casos de dor aguda do quadril. Royle ${ }^{(5)}$ propôs a ultra-sonografia e a radiografia na avaliação primária, apesar de ressaltar que a radiografia é de pouco valor nos estágios iniciais de infecção e para avaliar derrame articular.

Além disso, este autor demonstrou que um resultado anormal à cintilografia é pouco provável nos casos de ultra-sonografia sem alterações.

Eich et al $^{(3)}$ analisaram 89 casos de quadril doloroso, sendo $72 \%$ sinovite transitória, $9 \%$ pioartrite, $4 \%$ Perthes e $15 \%$ normais. Estes autores propuseram ultra-sonografia, VHS, hemograma e PCR em todos os casos, sendo a radiografia reservada a crianças menores do que 1 ano e maiores do que 8 anos. A punção articular guiada por ultra-sonografia foi indicada para casos de derrame articular associado a quadro clínico e alterações laboratoriais sugestivos de sépsis.

Nenhum caso de artrite séptica foi perdido. Dos 64 casos com sinovite transitória, apenas 11 foram puncionados e um fez radiografia. Incluir a radiografia na avaliação inicial é importante na faixa etária abaixo de 1 ano e acima de 8 anos devido a maior incidência de artrite séptica e espancamento no primeiro grupo e de epifisiólise no segundo grupo. Deve-se, ainda, indicar a radiografia nos casos com duração dos sintomas acima de duas semanas e nos casos de trauma, segundo estes autores.

\section{CONCLUSÃO}

Em decorrência da prevalência do quadril doloroso na criança, deve-se procurar abordar de maneira sistemática este quadro. A assistência sistemática do diagnóstico por imagem pode ser resumida seguindo os algoritmos 1,2 e 3. 
Algoritmos de diagnóstico POR IMAgem

algoritmo 1

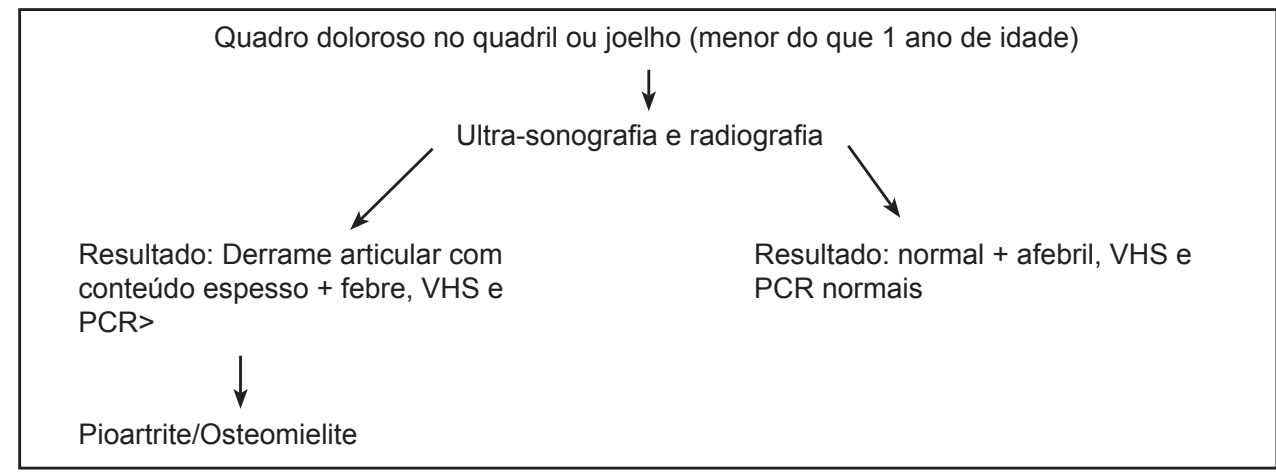

algoritmo 2

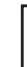

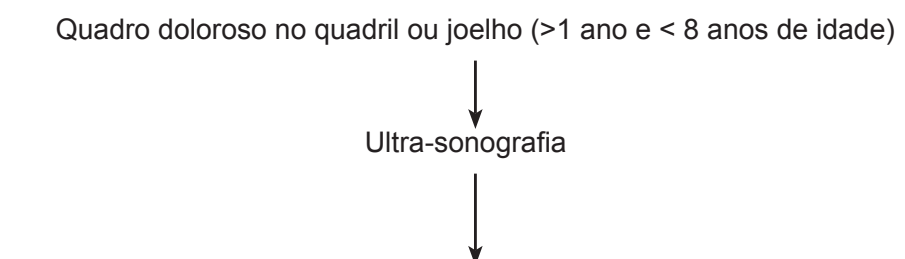

Resultado US: derrame articular anecogênico ou com debris

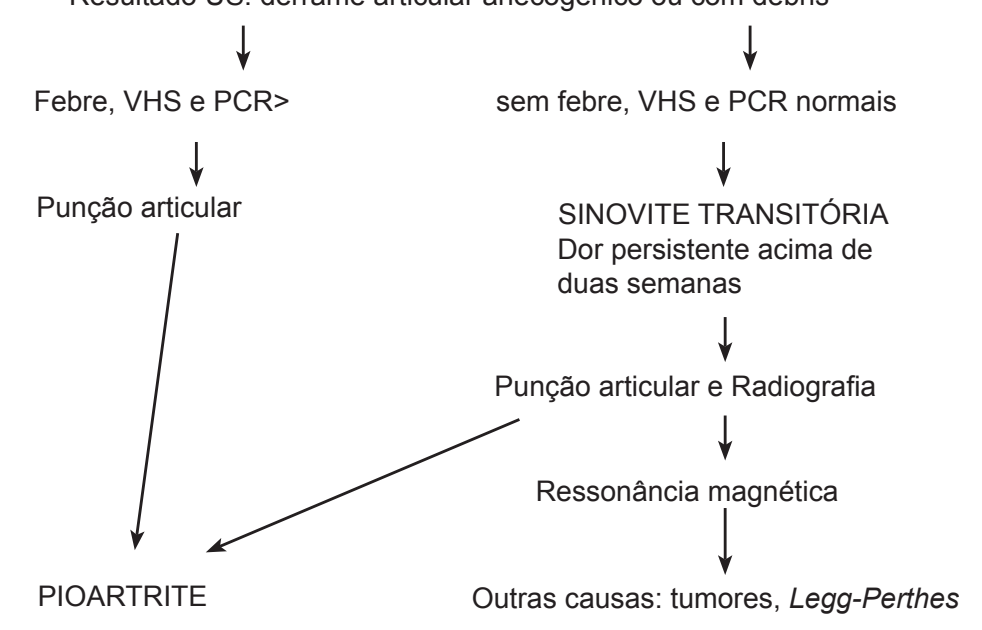

algoritmo 3

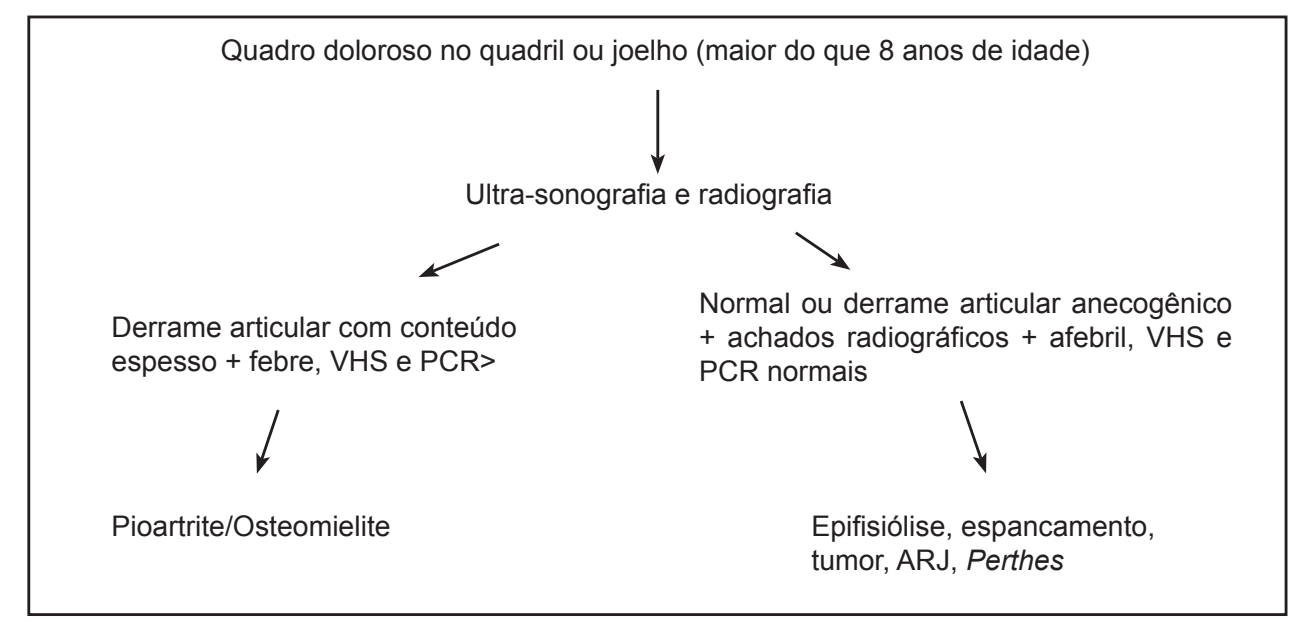




\section{REFERÊNCIAS}

1. Hollingworth P: Differencial Diagnosis and Management of Hip Pain in Childhood. Br J Rheumatol 34: 78-82, 1995.

2. Zacher J, Gursche A: Hip Pain. Best Prac Res Clin Rheumatol 17: 71-85, 2003.

3. Eich GF, Superti-Furga A, Umbricht FS, Willi UV: The Painful Hip: Evaluation of Criteria for Clinical Decision-Making. Eur J Ped 158: 923-928, 1999.

4. Swischuk LE. Pediatric Hip Pain: Emerg Radiol 9: 219-224, 2002.

5. Royle SG. Investigation of the Irritable Hip. J Ped Orthop 12: 396397, 1992.

6. Gabriel H, Fitzgerald SW, Myers MT, Donaldson JS, Poznansli AK: MR Imaging of Hip Disorders. RadioGraphics 14: 763-781, 1994.
7. Johnson K, Haig SF, Ehtisham S, Ryder C, Gardner-Medwin J: Childhood Idiopathic Chondrolysis of the Hip: MRI Features. Ped Radiol 33: 194-199, 2003.

8. Keats TE: The Pelvic Girdle. In: An Atlas of Normal Roentgen Variants that Simulate Disease, 2a ed., Chicago, Year Book Medical Publishers: 185-204,1979.

9. Hayes CW, Conway WF, Daniel WW: MR Imaging of Bone Marrow Edema Pattern: Transient Osteoporosis, Transient Bone Marrow Edema Syndrome, or Osteonecrosis. RadioGraphcs13: 1001-1011, 1993.

10. Stevens MA, El-Khoury GY, Kathol MH, Brandser EA, Chow S: Imaging Features of Avulsion Injuries. RadioGraphics 19: 665-672, 1999.

11. Ishedo A, Kuwajima SS: Epifisiólise. In: Ortopedia Pediátrica, $2^{\mathrm{a}} \mathrm{ed}$, Editora Atheneu: 208-289, 1998. 